\title{
Técnicas de identificação e meios de cultivo para crescimento de Bacillus thuringiensis utilizados no controle de mosquitos vetores: Mini revisão
}

\author{
Identification techniques and culture media for the growth of Bacillus thuringiensis used to control \\ vector mosquitoes: Mini review
}

Técnicas de identificación y medios de cultivo para el crecimiento de Bacillus thuringiensis utilizados para el control de mosquitos vectores: Mini revisión

Recebido: 07/06/2021 | Revisado: 15/06/2021 | Aceito: 18/06/2021 | Publicado: 30/06/2021

Juliete Lima Viana

ORCID: https://orcid.org/0000-0002-6008-3931

Universidade do Estado do Amazonas, Brasil E-mail: julieteviana_2009@hotmail.com

Katiane dos Santos Lobo

ORCID: https://orcid.org/0000-0003-3264-1905

Universidade do Estado do Amazonas, Brasil

E-mail: katianecx@hotmail.com

Maria dos Remédios Araújo Vieira Neta

ORCID: https://orcid.org/0000-0003-0788-1579 Universidade Federal de São Carlos, Brasil E-mail: remediosneta@gmail.com

Iolanda Cristina Silveira Duarte ORCID: https://orcid.org/0000-0002-9141-1010 Universidade Federal de São Carlos, Brasil E-mail: iolanda.duarte@gmail.com

Tiago Palladino Delforno

ORCID: https://orcid.org/0000-0002-1705-0763 Universidade Federal de São Carlos, Brasil E-mail: tiago.palladino@gmail.com Joelma Soares da Silva ORCID: https://orcid.org/0000-0002-5558-7916 Universidade Federal do Maranhão, Brasil E-mail: joelmasoares12@gmail.com

Valéria Cristina Soares Pinheiro

ORCID: https://orcid.org/0000-0002-4652-4884 Universidade Estadual do Maranhão, Brasi E-mail: pinheirovcs@gmail.com

Rosemary Aparecida Roque ORCID: https://orcid.org/0000-0002-8781-6170 Instituto Nacional de Pesquisas da Amazônia, Brasil E-mail: rosebio1996@yahoo.com.br

Wanderli Pedro Tadei

ORCID: https://orcid.org/0000-0002-0612-3285 Instituto Nacional de Pesquisas da Amazônia, Brasil E-mail:wptadeicurso@gmail.com

\begin{abstract}
Resumo
Bacillus thuringiensis $(\mathrm{Bt})$ é uma bactéria de interesse mundial, devido sua elevada toxicidade a uma ampla gama de insetos vetores de agentes patogênicos ao homem e pragas agrícolas. A ação inseticida de Bt é conferida pela presença de cristal proteico, que atuam como toxinas. Diversos estudos são realizados com intuito de selecionar linhagens de Bt de diferentes ecossistemas com ação mosquitocida para insetos vetores. Observa-se que o solo é o substrato mais utilizado para o isolamento de $\mathrm{Bt}$, sendo amplamente encontrado na natureza, predominantemente, na forma de esporos. A busca de novas linhagens de Bt em diferentes regiões do mundo tem como objetivo obter novas toxinas com ação inseticida, e que possam ser utilizadas na produção de biopesticidas. Para o cultivo das linhagens, são utilizados os meios Ágar Nutriente ou NYSM. Os meios de cultura possuem grande variedade de nutrientes, sendo ricos em carbono, nitrogênio e sais minerais, que são utilizados para induzir o crescimento dos microrganismos. Portanto, diversos estudos buscam aprimorar esses meios para o crescimento de $\mathrm{Bt}$, utilizando meios alternativos eficazes e econômicos, visando o controle de mosquitos vetores.
\end{abstract}

Palavras-chave: Entomopatogênico; Inseticida; Crescimento bacteriano; Controle biológico. 


\begin{abstract}
Bacillus thuringiensis $(\mathrm{Bt})$ is a bacterium of worldwide interest, due to its high toxicity to a wide range of insect vectors of pathogens to humans and agricultural pests. The insecticidal action of Bt is conferred by the presence of protein crystals, which act as toxins. Several studies are carried out in order to select Bt strains from different ecosystems with mosquitocidal action for vector insects. It is observed that the soil is the most used substrate for the isolation of $\mathrm{Bt}$, being widely found in nature, predominantly in the form of spores. The search for new Bt strains in different regions of the world aims to obtain new toxins with insecticidal action, which can be used in the production of biopesticides. For the cultivation of the strains, Nutrient Agar or NYSM media are used. Culture media have a wide variety of nutrients, being rich in carbon, nitrogen and mineral salts, which are used to induce the growth of microorganisms. Therefore, several studies seek to improve these means for the growth of Bt, using alternative effective and economical means, the control of vector mosquitoes.
\end{abstract}

Keywords: Entomopathogenic; Insecticide; Bacterial growth; Biological control.

\title{
Resumen
}

Bacillus thuringiensis $(\mathrm{Bt})$ es una bacteria de interés mundial, debido a su alta toxicidad para una amplia gama de insectos vectores de patógenos para humanos y plagas agrícolas. La acción insecticida de Bt se confiere por la presencia de cristales de proteínas, que actúan como toxinas. Se realizan varios estudios para seleccionar cepas de $\mathrm{Bt}$ de diferentes ecosistemas con acción mosquitocida para insectos vectores. Se observa que el suelo es el sustrato más utilizado para el aislamiento de Bt, encontrándose ampliamente en la naturaleza, predominantemente en forma de esporas. La búsqueda de nuevas cepas de Bt en diferentes regiones del mundo tiene como objetivo la obtención de nuevas toxinas con acción insecticida, que puedan ser utilizadas en la producción de bioplaguicidas. Para el cultivo de las cepas se utilizan medios de agar nutritivo o NYSM. Los medios de cultivo tienen una amplia variedad de nutrientes, ricos en carbono, nitrógeno y sales minerales, que se utilizan para inducir el crecimiento de microorganismos. Por ello, varios estudios buscan mejorar estos medios para el crecimiento de Bt, utilizando medios alternativos eficaces y económicos, el control de mosquitos vectores.

Palabras clave: Entomopatógeno; Insecticida; Crecimiento bacterial; Control biológico.

\section{Introdução}

A espécie Bacillus thuringiensis Berliner é um entomopatógeno de maior sucesso, apresentando múltiplas vantagens, principalmente quando comparado ao controle químico, que ocasionam sérios problemas à saúde humana e a natureza (Alves, 1998; Polanczyk e Alves, 2003; Bravo et al., 2011; Soares-da-Silva et al., 2017). Além disso, é uma das bactérias mais utilizadas na fabricação de inseticidas biológicos e, para o controle de insetos em todo o mundo (Polanczyk e Alves, 2003; Galzer e Azevedo Filho, 2016; Liu et al., 2016).

O interesse das pesquisas voltadas para o B. thuringiensis é devido sua elevada patogenicidade e toxicidade a uma ampla gama de insetos transmissores de agentes patogênicos ao ser homem e pragas agrícolas (Alves, 1998; Marrone, 2019; Saraiva et al., 2019). Portanto, diversos estudos em diferentes partes do mundo são realizados com o objetivo de selecionar novas linhagens de B. thuringiensis com elevada toxicidade (El-Kersh et al., 2016; Soares-da-Silva et al., 2017; Lobo et al., 2018).

B. thuringiensis é naturalmente encontrado em diferentes locais como no solo, grãos estocados, plantas, insetos mortos e água (Guz, Bugla-Ploskonska e Doroszkiewicz, 2009; Konecka et al., 2012; Reyaz, Gunapriya e Arulselvi, 2017; Argôlo-Filho e Loguercio, 2018). Relacionado aos insetos, tem-se constatado que esses organismos são altamente infectados por microrganismos, podendo está presente externa e internamente, mantendo a relação complexa entre eles. Os insetos mortos são fontes de alimento para B. thuringiensis no ambiente, servindo como substrato e matriz natural dos esporos. A ampla gama de substrato para reprodução de B. thuringiensis pode gerar variabilidade genética dessa bactéria em condições naturais (Alves, 1998; Ben-Dov, 2014; Raymond, 2017; Viana et al., 2020).

A ação inseticida de $B$. thuringiensis é conferida pela presença de cristal de proteínas produzido durante a fase de esporulação, que atuam como toxinas (Alves, 1998; Polanczyk e Alves, 2003; Fernández-Chapa et al., 2019). Essas proteínas são conhecidas como $\delta$-endotoxinas, que são compostas de duas famílias multigênicas, as proteínas Cry (Crystal) e Cyt 
(Citolíticas), as quais são tóxicas a insetos de diferentes ordens (Höfte e Whiteley, 1989; Bravo, Gill e Soberón, 2007; Van Frankenhuyzen, 2013; Badran et al., 2016; Zogo et al., 2019; Onofre et al., 2020).

Para a seleção de novas linhagens de B. thuringiensis com potencial de ação inseticida, um parâmetro importante é a adequação do crescimento bacteriano em laboratório, como verificação das exigências nutricionais, levando em consideração o próprio ambiente onde cada linhagem foi isolada. Nesse sentido, a escolha do meio de cultivo adequado é extremamente importante para o sucesso de produção da bactéria. Os meios de cultura para crescimento das bactérias, devem proporcionar a máxima produção com custo mínimo (Couch, 2000; Angelo, Vilas-Bôas e Castro-Gómez, 2010; Boniolo et al., 2012).

Os meios de cultivo utilizados para o crescimento de B. thuringiensis comumente possuem uma fonte de nitrogênio, carbono e sais minerais. A fonte de carbono fornece energia e matéria prima para muitas organelas celulares, o nitrogênio atua na síntese de proteínas e ácidos nucléicos e os sais minerais agem como cofatores no controle da osmolaridade celular (Angelo, Vilas-Bôas e Castro-Gómez, 2010; Boniolo et al., 2012). Nessa revisão foram identificados os meios de cultura mais comumente utilizados no crescimento de B. thuringiensis, as principais diferenças desses meios de cultivo e seus componentes nutricionais fundamentais. Além disso, também foi abordado as principais técnicas utilizadas na identificação dessa bactéria.

\section{Metodologia}

O presente estudo é uma síntese do conhecimento científico sobre a identificação de $B$. thuringiensis e os meios de cultura utilizados no crescimento da bactéria no controle de vetores. A escolha dos artigos foi realizada de modo atemporal, ou seja, independentemente do tempo.

A revisão foi produzida com base em livros científicos e artigos disponíveis nas bases de dados de indexação, como: Pubmed, Scielo, Wiley Online Library, cience Direct, Web of Science e Scopus. A busca de artigos nas diferentes bases de dados utilizou diferentes termos como: cultivos de Bacillus thuringiensis, seleção de Bacillus thuringiensis, identificação de Bacillus thuringiensis, Prospecção de Bacillus thuringiensis, Bacillus thuringiensis no controle de mosquitos vetores, culture media in the growth of Bacillus thuringiensis, Prospecting for Bacillus thuringiensis, selection of Bacillus thuringiensis in vector control. Após a seleção dos artigos científicos, os mesmos foram lidos, analisados e interpretados as principais informações para a fundamentação teórica do estudo. A partir da fundamentação teórica foram confeccionadas tabelas com os dados de cada artigo científico referente ao isolamento e meios de cultura utilizados no crescimento de B. thuringiensis.

\section{Bacillus thuringiensis}

A bactéria $B$. thuringiensis é um bastonete de 1 a $1,2 \mu \mathrm{m}$ de largura por 3 a $5 \mu \mathrm{m}$ de comprimento, comumente com motilidade. É gram-positiva, aeróbica, crescendo facultativamente em anaerobiose, na faixa de 10 a $45^{\circ} \mathrm{C}$. Desenvolvem esporos, de elípticos a cilíndricos, na posição central, com esporângio não claramente estendido e produzem um cristal proteico (Alves, 1998; Capalbo, Vilas-Bôas e Suzuki, 2005; Deng et al., 2014).

Em 1901, esta bactéria foi inicialmente analisada por Ishiwata, ocasionando mortalidade em larvas de bicho-da-seda, Bombyx mori (Lepidoptera: Bombycidae) (Linnaues, 1758), sendo chamada de Bacillus sotto. Posteriormente, em 1911, a bactéria foi novamente isolada por Berliner, apresentando aspectos da sua atividade entomopatogênica e o nomeou de $B$. thuringiensis em homenagem a província da Thuringia na Alemanha, local onde foi primeiramente descoberto (Glare e O’Callagham, 2000).

Embora o termo $B$. thuringiensis seja empregado para uma única espécie, levando em consideração aspectos taxonômicos, esta bactéria pertence a um complexo de várias espécies (B. anthracis, B. cereus, B. mycoides, B. thuringiensis e B. weihenstephnensis). Este complexo é denominado B. cereus (Polanczyk e Alves, 2003; Ehling-Schulz, Lereclus e Koehler, 2019). 
O número de células de $B$. thuringiensis obtidas em isolamento varia entre $10^{2}$ e $10^{4}$ unidades formadoras de colônia (UFC) por grama de solo, enquanto que em plantas este número possui uma taxa bem mais baixa (Damgaard, 2000).

Dentre as bactérias que possuem patogenicidade a insetos, o B. thuringiensis é o principal componente ativo utilizado comercialmente nos biolarvicidas (Liu et al., 2016). A espécie Bacillus thuringiensis var. israelensis (Bti) é a linhagem que apresenta maior atividade tóxica para mosquitos e é utilizada como padrão, sendo indicada no controle de vetores em várias regiões do planeta. O grande sucesso desta bactéria como agente de controle biológico se dá devido à produção, durante a esporulação, de um cristal de proteínas, que contêm toxinas inseticidas, chamadas de $\delta$-endotoxinas (Damgaard, 2000; Delécluse, Juárez-Pérez e Berry, 2000; Saraswathy e Kumar, 2004; Sanchis, 2011; Deng et al., 2014; Onofre et al., 2020).

O B. thuringiensis oferece uma diversidade de vantagens, como segurança ambiental, pois atua somente na espécie alvo e suas toxinas não se acumulam no meio ambiente; ótima durabilidade no ambiente, apresentando eficácia no campo de até 90 dias, em locais protegidos dos raios solares; capacidade de reciclagem em larvas mortas, com isso os esporos podem germinar dentro do cadáver das larvas, mantendo-se assim no ambiente; além de apresentar uma diversidade de toxinas inseticidas, o que irá dificultar a seleção de mosquitos com resistência (Habib e Andrade, 1998; Polanczyk e Alves, 2003; Soares-da-Silva et al., 2017).

\section{Mecanismo de ação das toxinas Cry e Cyt de Bacillus thuringiensis}

A atividade larvicida da bactéria $B$. thuringiensis é conferida à produção de um cristal proteico, que irá conter as delta-endotoxinas, sendo as proteínas Cry (Cristal) as mais relevantes, e as Cyt (Citolíticas) atuando em sinergismo com as toxinas do cristal proteico. Estas proteínas são sintetizadas durante o processo de esporulação do B. thuringiensis, em condições limitadas de crescimento, e são codificadas por diferentes genes chamados genes cry e cyt (Agaisse e Lereclus, 1995; De Maagd et al., 2003; Saraswathy e Kumar, 2004; Pérez et al., 2005; Fernández-Chapa et al., 2019).

O cristal de proteínas dessa bactéria é considerado como uma pró-toxina, sendo uma forma inativa, que em contato com meio alcalino ou em solução de enzima proteolítica, ocorre a clivagem desta pró-toxina, resultando em moléculas de tamanhos variados, as comumente chamadas de Cry e Cyt (Kuo e Chak, 1996; Yamamoto e Dean, 2000; Bravo et al., 2005; Zhong et al., 2007). Os esporos também podem contribuir com a atividade patogênica por meio da ação sinérgica realizada com as delta-endotoxinas (Johnson e McGaughey, 1996).

As proteínas Cry apresentam atividade tóxica para os insetos, quando as larvas se alimentam desses cristais. Deste modo, após a ingestão, os cristais são solubilizados no $\mathrm{pH}$ alcalino, que em presença de enzimas digestivas, tornam-se tóxicos e são convertidas em quatro ou mais polipeptídios de delta-endotoxinas. As toxinas hidrolisadas atravessam a membrana peritrófica, ligam-se aos receptores específicos na membrana apical das células colunares do intestino médio, intervindo no gradiente iônico e no balanço osmótico das células da membrana, formando poros e, causando ruptura na célula e desintegração do intestino médio. Portanto, a larva sofre consequente morte por inanição, tornando-se incapaz de absorver os nutrientes necessários (Figura 1) (Höfte e Whiteley, 1989; Bravo, 1997; Copping e Menn, 2000; Bergman et al., 2007).

A atividade patogênica a insetos dessa bactéria está associada com a síntese dessas proteínas que possuem alta atividade tóxica e exclusivas para insetos de diversas ordens e alguns invertebrados (Höfte e Witeley, 1989; Glare e O'Callangham, 2000; Zogo et al., 2019). 
Figura 1. Representação esquemática do modo de ação das toxinas de Bacillus thuringiensis subsp. israelensis em larva de mosquito.

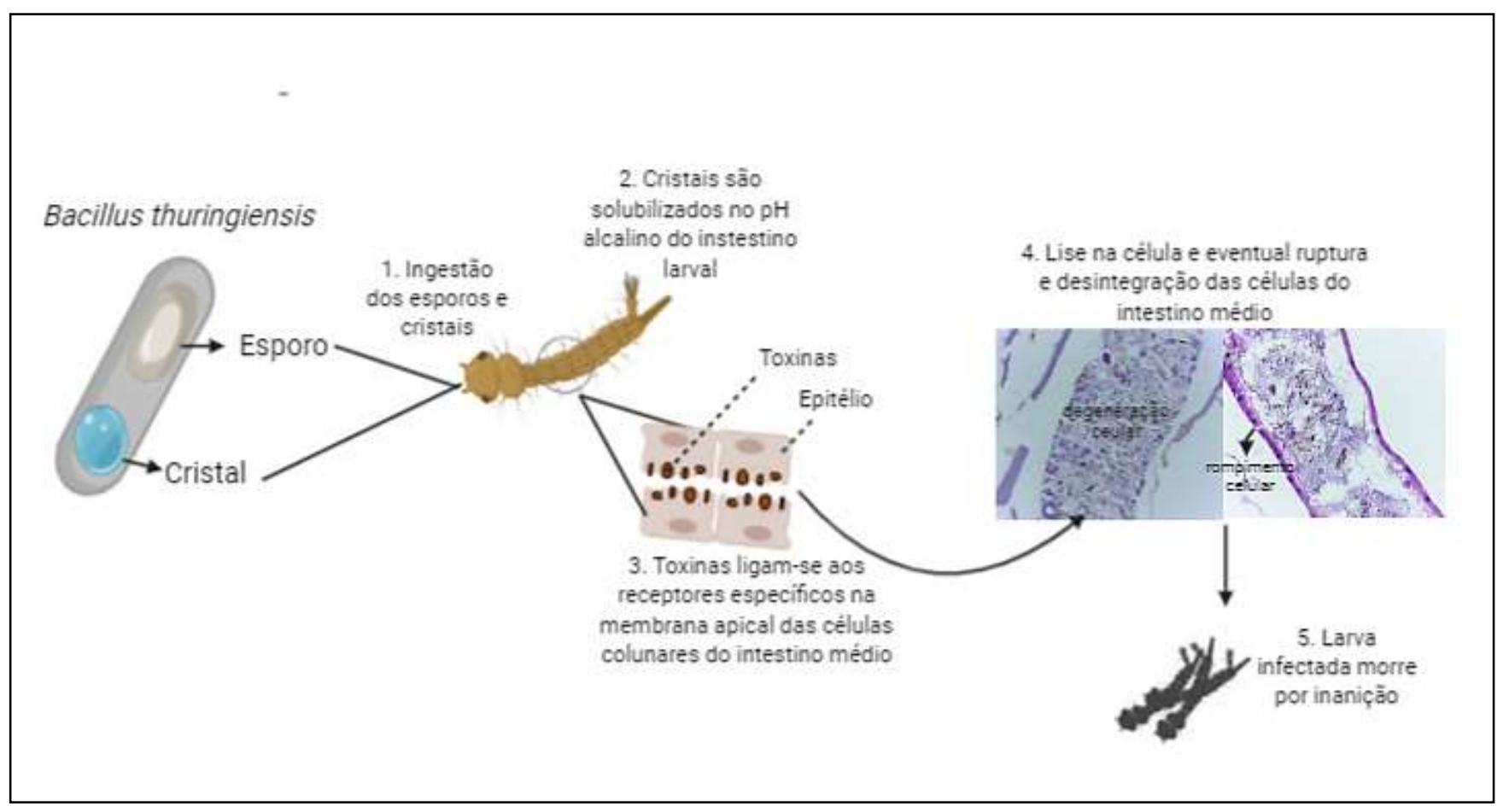

Fonte: Esquema realizado por Vieira-Neta no Created in BioRender e figuras do epitélio intestinal de Viana et al. (2021).

Diversas ordens de insetos são suscetíveis às linhagens de B. thuringiensis, dentre as mais estudadas estão, Lepidoptera, Coleoptera por serem importantes pragas agrícolas e Díptera, especialmente as espécies vetores de doenças. Além de insetos são citados na literatura os nematóides, ácaros, entre outros organismos (Kuo e Chak, 1996; Yamamoto e Dean, 2000; De Maagd et al., 2003; Van Frankenhuyzen, 2009, 2013).

As toxinas de B. thuringiensis são compostas por três domínios, o domínio I, relacionado à inserção e formação de poros na membrana; o II, responsável pelo reconhecimento do receptor e, pela ação específica da toxina para a espécie-alvo; e o domínio III, em que sua função ainda não está totalmente esclarecida, mas acredita-se estar envolvida com as duas funções dos domínios anteriores, além de tornar a toxina estável (Saraswathy e Kumar, 2004).

Pesquisas sobre a toxina de $B$. thuringiensis, mostram a associação entre os três domínios para ocasionar a atividade larvicida de B. thuringiensis. Saraswathy e Kumar (2004) delinearam a engenharia das diferentes $\delta$-endotoxinas, levando à compreensão do seu modo molecular de atuação e constituição de novas toxinas com maior patogenicidade e ação específica. A atividade tóxica das proteínas está associada ao componente $\mathrm{N}$-terminal, enquanto que o componente C-terminal determina a formação da estrutura do cristal proteico ( $\mathrm{Li}$, Carroll e Ellar, 1991). A composição da inclusão cristalina e as estruturas das toxinas originam a formação do cristal, que pode ser bipiramidal, cubóide, rombóide, ovóide, esférico, retan gular ou sem forma determinada (Habid e Andrade, 1998).

A maioria das linhagens de B. thuringiensis são capazes de produzir mais de um tipo de cristal. Os cristais são formados por diferentes proteínas Cry e/ou Cyt, como ocorre na espécie B. thuringiensis subsp. israelensis (Bti), que possui cinco genes que codificam proteínas Cry e dois genes codificadores de Cyt, localizados no mesmo plasmídeo com massa molecular de 72 MDa (González e Carlton, 1984; Lereclus et al., 1989; Berry et al., 2002). Esses genes das proteínas do cristal de proteínas de B. thuringiensis estão presentes em plasmídeos conjugativos, facilitando a recombinação e troca destes 
elementos, assim, fornece um importante mecanismo de geração de novas especificidades (Aronson, 1993; Berry et al., 2002; Espinasse et al., 2003).

A multiplicidade de proteínas Cry e Cyt são consequência de contínuos esforços na investigação por toxinas com características apropriadas para controlar biologicamente os insetos de importância agrícola e transmissores de doenças (Pigott e Ellar, 2007; Saraiva et al., 2019). Compreendendo mais de 400 genes cry e aproximadamente 37 genes cyt já identificados. As proteínas Cry estão classificadas em cerca de 74 grupos reunidos em diferentes subgrupos, além da existência de três grupos de toxinas Cyt (Crickmore et al., 2020). As toxinas Cry especificamente com ação para dípteros vetores de doenças abrangem cerca de 20, sendo que consecutivamente são descritos novos genes e, por conseguinte, novas toxinas (Van Frankenhuyzen, 2009, 2013).

Um dos exemplos de trabalhos de isolamento e avaliação da patogenicidade de novas linhagens de B. thuringiensis, foi realizado em 2009, na China, onde foi isolado do solo uma nova linhagem de B. thuringiensis, que demostrou atividade entomopatogênica para larvas de Aedes aegypti vinculada à mesma descoberta, encontrou-se também uma nova toxina Cry diferente das atualmente conhecidas, com ação para o mesmo vetor (Tan et al., 2009).

Especialmente, devido à crescente utilização das proteínas Cry e Cyt, produzidas por essa bactéria no controle biológico de insetos de importância epidemiológica, há também a preocupação com a manipulação de resistências de insetos alvo às $\delta$-endotoxinas produzidas pelo $B$. thuringiensis já conhecidas. E como essas toxinas não oferecem risco à saúde humana e outras espécies benéficas à natureza, a sua utilização para controle de insetos vetores tornam-se conveniente (Carozzi et al., 2001; Silva, 2008).

Desse modo, a investigação de novas linhagens de B. thuringiensis com potencialidades diferentes das atualmente conhecidas, mostra-se como uma das prioridades de pesquisas em várias regiões do mundo, objetivando obter, isolar e caracterizar linhagens promissoras e com toxinas diferenciadas das que já existem, podendo ser utilizadas na produção de biolarvicidas (Schnepf e Whiteley, 1981; Barreto, 2005; Medeiros et al., 2006; El-Kersh et al., 2016; Soares-da-Silva et al., 2017; Lobo et al., 2018).

\section{Isolamento, identificação e toxicidade de Bacillus thuringiensis para mosquitos vetores}

Devido ao sucesso de $B$. thuringiensis no controle de vetores, diversos estudos são realizados para selecionar isolados com ação mosquitocida (Campanini et al., 2012; Soares-da-Silva et al., 2015; Tissera et al., 2018; Vieira-Neta et al., 2020). Geralmente, os trabalhos de seleção de linhagens de B. thuringiensis para mosquitos são iniciados com a busca pelo complexo de proteínas Cry e Cyt, toxinas encontradas na cepa padrão Bti (cry4Aa, cry4Ba, cryloAa, cryl1Aa, cryl1Ba, cytlAa, cytlAb e cy $2 \mathrm{Ba}$ ), pois os genes presentes nos isolados é uma forma de prever a atividade larvicida. No entanto, muitos trabalhos preferem selecionar linhagens selvagens, tendo em vista, que estas podem apresentar maior variabilidade genética (Van Frankenhuyzen, 2009; da Costa et al., 2010; Cantón et al., 2011; Crickmore et al., 2020).

O solo é o substrato comumente utilizado para a seleção de B. thuringiensis (Soares-da-Silva et al., 2017; Gobatto et al., 2010; Soares-da-Silva et al., 2015; Monnerat et al., 2005; Vieira-Neta et al., 2020), pois essa bactéria é amplamente encontrada na natureza predominantemente na forma de esporos, que podem permanecer viáveis por longos períodos de tempo (de Maagd et al., 2003). De acordo com Wang et al. (2003) o B. thuringiensis é encontrado em todos os ambientes terrestres e também em insetos mortos plantas e detritos. B. thuringiensis possui capacidade de permanecer no solo em diversas condições ambientais, sendo facilmente transportada por animais, vento e chuvas. A presença de componentes químicos no solo como $\mathrm{Ca}, \mathrm{Cu}, \mathrm{Fe}$ e Zn são importantes para o desenvolvimento da bactéria no ambiente (Glare e O’Callagham 2000; Polanczyk, 2004). 
Diferentes hipóteses explicam sobre a permanência de B. thuringiensis no solo, Meadows (1993) relata que $B$. thuringiensis é depositado no solo por folhas e insetos, dificilmente desenvolve-se no solo. Essa bactéria também pode ser patógeno de insetos do solo que apresentem pouca importância econômica, com os quais poucos estudos foram realizados. Pressupõe também que $B$. thuringiensis pode desenvolver-se no solo quando existem nutrientes suficientes, obtidos de resíduos orgânicos em decomposição. E que a afinidade de B. thuringiensis e B. cereus, com o qual B. thuringiensis pode trocar material genético, possibilitando sua permanência no ambiente. Outra proposição para a variação de B. thuringiensis nas regiões brasileiras podem estar relacionadas às atividades agrícolas, tipos de solo e método de isolamento desenvolvido (Gobatto et al., 2010).

A quantidade de isolados obtidos de diferentes regiões brasileiras varia bastante (Tabela 1), o que pode influenciar no percentual de $B$. thuringiensis em uma localidade é a dificuldade e a comparação entre estudos, referente ao método de isolamento empregado, pois estes não são padronizados, havendo uma grande diversidade entre os grupos de pesquisa (Carozzi et al., 1991; da Silva, Dias e Monnerat, 2002; Polanczyk, Zanúncio e Alves, 2009). No entanto, existe um método preconizado pela Organização Mundial da Saúde (WHO, 1985). Outros fatores que podem influenciar na quantidade de linhagens de $B$. thuringiensis são: a escolha do substrato, o método de coleta em campo e o processo de identificação da espécie.

Em estudo realizado por Soares-da-Silva et al. (2015) foi relatado que de 57 linhagens de B. thuringiensis obtidas de áreas florestais da Amazônia apenas 8,8\% apresentaram atividade larvicida contra Ae. aegypti e somente uma (BtAM-27) expressou cinco genes (cry4Aa, cry4Ba, cry10Aa, cryl1Aa e cryl1Ba), os quais são descritos na literatura como responsáveis pela toxicidade de dípteros, apesar dos cincos isolados apresentaram toxicidade, somente duas linhagens (IBt-07 e IBt-28) exibiram os menores valores de $\mathrm{CL}_{50}$ com 0,0011 e $0,0014 \times 10^{5}$, respectivamente.

Em outro estudo, Soares-da-Silva et al. (2017) relataram que de 553 linhagens de B. thuringiensis testadas contra Ae. aegypti apenas 37 apresentam patogenicidade, destes 12 proporcionaram mortalidade de $100 \%$ das larvas em $24 \mathrm{~h}$ e foram utilizadas em ensaios de toxicidade. Os autores mostraram que duas linhagens BtMA-690 e BtMA-1114 apresentaram toxicidade igual a cepa padrão Bti, e o mesmo valor de $\mathrm{CL}_{50}(0,003 \mathrm{mg} / \mathrm{L})$ foi observado após 48 h de exposição. No estudo também foi verificado as toxinas Cry, Cyt e Chi importantes na toxicidade para mosquitos vetores.

Lobo et al. (2018) reportaram que de 300 linhagens analisadas quanto a patogenicidade contra as larvas de Ae. aegypti, 12 foram patogênicas, e apenas uma linhagem BtMA-401 apresentou CL50 de 0,004 × $10^{7}$ esporos/mL. Quando submetidos a análise molecular mediante PCR, 10 linhagens apresentaram um ou mais genes cry e cyt dípteros-específico. Campanini et al. (2012) caracterizaram por meio de técnicas moleculares, mediante RNA ribossomal 16S (ou 16S rRNA), 76 linhagens de Bt, e verificaram que oito isolados apresentavam os genes cry $4 A a$, cry $4 B$ a ou cryl0Aa, destes sete apresentaram mortalidade às larvas de Ae. aegypti. A presença de genes, por isso, não significa que a linhagem apresente toxicidade, pois para isso ocorrer é necessário que as proteínas sejam expressas.

Ootani et al. (2011) relataram a investigação de 101 linhagens de B. thuringiensis de diferentes localidades do estado do Tocantins, destas somente a linhagem A-392 apresentou excelente atividade larvicida contra Ae. aegypti e mediante análise proteica apresentaram proteínas de massa molecular de aproximadamente $80 \mathrm{kDa}$ correspondente ao tamanho esperado para a estirpe padrão Bti. As proteínas Cry apresentam massa molecular entre 40 a 140 kDa e as toxinas Cyt apresentam proteínas de massa molecular de 27-30 kDa. Gobatto et al. (2010) selecionaram 231 isolados, destes 35 foram submetidos a bioensaios de patogenicidade e toxicidade, do qual $31 \%$ apresentaram atividade larvicida contra Culex quinquefasciatus e um isolado apresentou valor de $\mathrm{CL}_{50}$ semelhante a Bti.

Vieira-Neta et al. (2020) estudando áreas de restinga e manguezais analisaram 232 linhagens de B. thuringiensis, e relataram que uma linhagem, BtMA-750, apresentou alta toxidade contra Ae. aegypti e exibiu produtos de amplificação para nove genes díptero-específico presente na cepa padrão Bti. No entanto, evidenciou-se que novos estudos devem ser realizados 
com esta linhagem, a fim de elucidar se os genes estão expressando as proteínas com ação larvicida, pois a CL50 foi de 0,004 $\mathrm{mg} / \mathrm{mL}$ em comparação ao Bti que apresentou CL ${ }_{50}$ de $0.003 \mathrm{mg} / \mathrm{mL}$.

$\mathrm{Na}$ literatura, também é bastante relatado o estudo das linhagens que estão depositadas em diferentes coleções de entomopatógenos no Brasil (Praça et al., 2004; Monnerat et al., 2005; Soccol et al., 2009), nessas coleções estão depositadas linhagens obtidas de uma variedade de substratos provenientes de diferentes regiões brasileiras. Portanto, o estudo destas linhagens é de extrema importância, pois possibilita encontrar aquelas com variabilidade genética e elevada toxicidade conta insetos vetores.

Praça et al. (2004) analisaram 300 linhagens de B. thuringiensis proveniente do Banco de Germoplasma de Bactérias Entomopatogênicas da Embrapa Recursos Genéticos e Biotecnologia, e relataram que a linhagem S234 e S997 apresentaram patogenicidade contra Ae. aegypti e Cu. quinquefasciatus. No entanto, apresentaram valor de CL50 para Ae. aegypti e para Cu. quinquefasciatus superior ao do Bti (S234 de 4,9200 mg/mL e S997 de 4,4900 mg/mL para Ae. aegypti e S234 de 7,2600 $\mathrm{mg} / \mathrm{mL}$ e $\mathrm{S} 997$ de $31,0300 \mathrm{mg} / \mathrm{mL}$ para Cu. quinquefasciatus, Ae. aegypti 0,0016 mg/mL e Cu. quinquefasciatus de 0,0096 para Bti) o que demonstram que comparado a estirpe padrão possui menos efetividade e amplificaram os genes crylAa, crylAb, crylAc, crylB e cry2.

Monnerat et al. (2005) também realizaram estudos com 210 linhagens de B. thuringiensis isoladas da água e do solo provenientes da coleção de Bacillus spp. entomopatogênicos do Embrapa Recursos Genéticos e Biotecnologia. Das seis linhagens de $B$. thuringiensis tóxicas a mosquitos vetores analisados nos bioensaio seletivos, quatro linhagens apresentaram atividade larvicida contra Ae. aegypti, duas contra ambas as espécies Ae. aegypti e Cu. quinquefasciatus. As linhagens apresentaram valores de CL50 semelhantes entre si (Ae. aegypti de 6.8 a $42 \mathrm{mg} / \mathrm{mL}$ e Cu. quinquefasciatus de 0.073 a 0.089 $\mathrm{mg} / \mathrm{mL}$ ) e maior que a estirpe padrão Bti (Ae. aegypti de $1.1 \mathrm{mg} / \mathrm{mL}$ e e Cu. quinquefasciatus de 0.034) e nenhum dos isolados apresentaram tamanho esperado para os genes cry4, cryll e cytlA.

Estudos visando a detecção de genes mosquitocidas no controle do Ae. aegypti foram realizados com 1073 linhagens de B. thuringiensis de diferentes regiões do Brasil provenientes da coleção do Laboratório de Genética de Bactérias e Biotecnologia Aplicada, Unesp, Campus de Jaboticabal, no qual 45 isolados que apresentaram genes cry e cyt foram selecionados para os testes de patogenicidade e toxicidade, destes 13 apresentaram atividade larvicida para larvas de Ae. aegypti e também foi verificado linhagens com os menores valores de CL 50 e CL90 (da Costa et al., 2010). Soccol et al. (2009) também analisaram 12 linhagens de B. thuringiensis, cepas estas, oriundas do Banco de Cepas da Divisão de Engenharia de Bioprocessos e Biotecnologia para a produção endotoxina no controle de Ae. aegypti.

É notório que o solo é o substrato mais utilizado para prospecção de $B$. thuringiensis, porém, apesar da quantidade elevada de linhagens obtidas dos mais variados substratos, são poucas que apresentam toxicidade superior a cepa padrão Bti, isso pode ocorrer devido o Bti expressar os genes cry4Aa, cry4Ba, cryl0Aa, cryl1Aa, cryl1Ba, cyt1Aa, cyt1Ab e cy2Ba, responsáveis pela produção de proteínas Cry e Cyt. Além disso, as linhagens selvagens apesar de apresentar os genes dípteros específicos, alguns não produzem as proteínas, portanto os estudos devem ser voltados para elucidar se esses genes estão sendo inibidos. Vale ressalvar também que algumas linhagens extremamente tóxicas, apresentam apenas poucos genes comparado ao Bti, e isso é uma desvantagem, pois quanto maior o número de genes melhor combinação entre eles, o que resulta em menor probabilidade dos insetos adquirirem resistência ao Bti. 
Tabela 1. Amostragem de isolados de Bacillus thuringiensis utilizados no controle de vetores.

\begin{tabular}{lccl}
\hline Local de Amostragem & Substrato & ${ }^{*} \mathbf{B t}$ & Referência \\
\hline Amazônia, Brasil & Solo & 57 & Soares-da-Silva et al. (2015) \\
\hline $\begin{array}{l}\text { Banco de Bacilos Entomopatôgenico do } \\
\text { Maranhão-BBENMA }\end{array}$ & Solo & 153 & Soares-da-Silva et al. (2017) \\
\hline & Solo & 85 & Soares-da-Silva et al. (2017) \\
\cline { 2 - 4 } & Insetos mortos & 244 & Soares-da-Silva et al. (2017) \\
\cline { 2 - 4 } & Solo & 71 & Soares-da-Silva et al. (2017) \\
\cline { 2 - 4 } & Solo & 232 & Vieira-Neta et al. (2020) \\
\hline São Paulo, Brasil & Solo & 383 & Lobo et al. (2018) \\
\hline Tocantins, Brasil & Solo & 76 & Campanini et al. (2012) \\
\hline $\begin{array}{l}\text { Rio Grande do Sul, Brasil } \\
\text { *Banco de Germoplasma de Bactérias }\end{array}$ & Solo & 101 & Ootani et al. (2011) \\
\cline { 2 - 4 } Entomopatogênicas & Solo e insetos & 231 & Gobatto et al. (2010) \\
\hline *Coleção do Laboratório de Genética de & mortos & 300 & Praça et al. (2004) \\
Bactérias e Biotecnologia Aplicada & Solo e água & 210 & Monnerat et al. (2005) \\
\hline $\begin{array}{l}\text { *Banco Divisão de Engenharia de } \\
\text { Bioprocessos e Biotecnologia }\end{array}$ & - & 1073 & da Costa et al. (2010) \\
\hline
\end{tabular}

*isolados obtidos de diferentes regiões brasileiras e depositados em diferentes coleções; \#quantidade de isolados de Bacillus thuringiensis; - Não especificado. Fonte: Autores.

\section{Meios de cultura utilizados no crescimento de Bacillus thuringiensis no controle biológico de mosquitos vetores}

Observa-se que o ágar Nutriente (Extrato de Carne, Extrato de Levedura; Peptona, Cloreto de Sódio e Agar) ou o meio Nutrient Yeast Extract Salt Médium - NYSM (caldo nutriente, extrato de levedura, $\mathrm{MnCl}_{2}, \mathrm{MgCl}_{2}, \mathrm{CaCl}_{2}$ ) são muito utilizados no isolamento e crescimento de B. thuringiensis utilizado no controle de vetores (Polanczyk et al., 2004; da Costa et al., 2010; Gobatto et al., 2010; Ootani et al., 2011; Campanini et al., 2012; Soares-da-Silva et al., 2015; Soares-da-Silva et al., 2017; Lobo et al., 2018). O ágar Nutriente é um meio simples, de fácil preparação e com várias finalidades em laboratório de microbiologia, usado também para observar esporulação de espécies de bacilos Gram positivos no caso de B. thuringiensis. A peptona e o extrato de carne fornecem fontes de nutrientes como nitrogênio, vitaminas, minerais e aminoácidos. O extrato de levedura é uma fonte de vitaminas essenciais para o crescimento de bactérias. O cloreto de sódio mantém o balanço osmótico e o ágar bacteriológico é o agente solidificante. O NYSM é um meio de cultura de baixo custo e disponível para a produção de bactérias com atividade larvicida. Os meios são utilizados com finalidade de cultura e isolamento de microrganismos, uma grande variedade de processo e de preparações de nutrientes é utilizada para induzir o crescimento e a reprodução de microrganismos, sendo a maioria meios convencionais. No entanto, alguns estudos analisaram meios de culturas alternativos com o objetivo de obter um aumento na produção de células de B. thuringiensis.

Diferentes estudos buscam aprimorar as condições de cultivo de B. thuringiensis, devido a produção das endotoxinas dependerem dos nutrientes presentes no meio de fermentação. Portanto, a produtividade das delta endotoxinas pode ser melhorada mediante manipulação dos parâmetros nutricionais, condições ambientais e melhoria na seleção de fontes de carbono e nitrogênio (Salama et al., 1983; Rossa et al., 1990). Liu e Tzeng et al. (1998) e Sarrafzadeh et al. (2012) realizaram 
estudos sobre os efeitos das composições dos meios de cultivo no crescimento de B. thuringiensis, e demonstram com os resultados obtidos que para a comercialização bem-sucedida da produção de B. thuringiensis é necessário o desenvolvimento de uma fermentação ideal. A tabela 2 mostra a composição de diferentes meios alternativos para crescimento do Bti e a toxicidade contra diferentes mosquitos.

Poopathi e Abidha (2011) elaboraram um meio de cultura utilizando resíduos de casca de café para a produção de biopesticida, e relataram que as delta endotoxinas produzidas pelo Bti foram semelhantes as produzidas no meio convencional NYSM. Além disso, as toxinas mostraram excelente atividade larvicida contra $\mathrm{Cu}$. quinquefasciatus, Anopheles stephensi e Ae. aegypti, e produção de delta endotoxinas. Em outro estudo Poopathi e Abidha (2012) analisaram a viabilidade de resíduos de sedimentos de manteiga clarificada como meio de cultura na produção de bactérias mosquitocidas. A densidade óptica (650 $\mathrm{nm}$ ) do meio, no intervalo de $6 \mathrm{~h}$ a 72h atingiu uma absorbância de 0,5 para 2,62 indicando que houve excelente crescimento celular, ao final da fermentação (72h) ocorreu rendimento de $9,7 \mathrm{~g} / \mathrm{L}$ de biomassa e produção em torno de 2,5 g/L de toxinas (esporos/cristal) com atividade larvicida contra mosquitos vetores. Este resultado foi semelhante ao obtido com meio NYSM.

Poopathi e Kumar (2003) analisaram três meios de cultura alternativos como extrato de batata, extrato de batata açucarado e extrato de batata combinado com grão-de-bico para o crescimento e produção de toxinas de Bti, que mostrou, nos bioensaios, toxicidade às larvas de $\mathrm{Cu}$. quinquefasciatus, An. stephensi e Ae. aegypti, a toxicidade foi igualmente comparável com o meio de cultivo convencional Luria-Bertani- LB (Triptona, Extrato de Levedura e Cloreto de Sódio: 1:0.5:1 wt:vol). Ernandes, Del Bianchi e Oliveira (2013) utilizando o processo de fermentação submersa visando obter um crescimento celular de Bti no controle de Ae. aegypti, além da produção de esporos verificou que a milhocina, subproduto agroindustrial proveniente do processamento do milho, possui melhor eficiência quando comparada com a triptose. O fato da milhocina ter apresentado melhor resultado pode estar relacionado com a composição química, pois a mesma é uma excelente fonte de carboidratos solúveis, aminoácidos e minerais, que são nutrientes importantes para o metabolismo dos microrganismos.

Devidas, Pandit e Vitthalrao (2014) avaliaram fonte de carbono convencional e não convencional e fontes de nitrogênio para a produção de biomassa e esporo/cristal e determinaram a eficácia do custo benefício de substratos potenciais na produção de $B$. thuringiensis, e observou um aumento significativo na produção de biomassa na utilização de glicose 6.30 $(0.03)^{\mathrm{a}} \mathrm{g} / \mathrm{L}$, banana $5.87(0.08)^{\mathrm{b}} \mathrm{g} / \mathrm{L}$ e beterraba $5.10(0.11)^{\mathrm{b}} \mathrm{g} / \mathrm{L}$. Análises de custo-benefício revelaram que a produção de biopesticidas a partir de meios alternativos é altamente econômica, no qual mostraram resultados eficazes, e nos testes de toxicidade foi observado que o efeito tóxico foi aumentado duas vezes ( $\mathrm{CL}_{50}$ 1.57) em comparação ao meio LB ( $\mathrm{CL}_{50} 4.02$ ), quando utilizaram feijão e soja ( $\left.\mathrm{CL}_{50} 3.17\right)$ como meio de cultivo, obtiveram resultados próximos ao meio LB ( $\left.\mathrm{CL}_{50} 4.02\right)$.

Prabakaran et al. (2008) desenvolveram um meio de cultivo à base de água de coco e verificaram um rendimento da massa célula de $3.1 \mathrm{~g} / \mathrm{L}$, esporulação de $3.4 \times 10^{11}$ e atividade larvicida contra as larvas de Ae. aegypti por meio do cultivo de Bti, verificando resultados similares aos obtidos com o meio convencional (NYSM). As fontes alternativas mingau e farinha de peixe, farinha de soja, farelo de trigo e pó de bolo de amendoim possuem excelente resultados no cultivo de B. thuringiensis (Ghribi, Zouari e Jaoua, 2005; Prabakaran e Balaraman, 2006). 
Tabela 2. Componentes dos meios de cultivo alternativos utilizados no crescimento de Bacillus thuringiensis.

\begin{tabular}{|c|c|c|c|}
\hline Meio de cultivo alternativo & Bti & \multirow{2}{*}{ Mosquito } & \multirow{2}{*}{ Referência } \\
\hline Composição (m/v) & $\mathbf{C L}_{50}$ & & \\
\hline \multirow{3}{*}{$\begin{array}{l}\text { Resíduo da casca de café (proteína } 7,0 \% \text {, carboidrato } \\
57,8 \% \text {, lipídio } 0,3 \% \text {, cinzas } 5,4 \% \text { ) }\end{array}$} & $0,0035 \mathrm{mg} / \mathrm{L}$ & C. quinquefasciatus & \multirow{3}{*}{$\begin{array}{c}\text { Poopathi e } \\
\text { Abidha } \\
(2011)\end{array}$} \\
\hline & $0,0056 \mathrm{mg} / \mathrm{L}$ & An. Stephensi & \\
\hline & $0,0073 \mathrm{mg} / \mathrm{L}$ & Ae. Aegypti & \\
\hline \multirow{3}{*}{ Extrato do subproduto da manteiga clarificada $(30 \mathrm{~g} / \mathrm{mL})$} & $0,0036 \mathrm{mg} / \mathrm{L}^{*}$ & C. quinquefasciatus & \multirow{3}{*}{$\begin{array}{c}\text { Poopathi e } \\
\text { Abidha } \\
(2012)\end{array}$} \\
\hline & $0,0058 \mathrm{mg} / \mathrm{L}^{*}$ & An. Stephensi & \\
\hline & $0,0075 \mathrm{mg} / \mathrm{L}^{*}$ & Ae. Aegypti & \\
\hline Extrato de batata & $1,58 \mu \mathrm{g} / \mathrm{L}$ & \multirow{3}{*}{ C. quinquefasciatus } & \multirow{9}{*}{$\begin{array}{c}\text { Poopathi e } \\
\text { Kumar } \\
(2003)\end{array}$} \\
\hline Extrato de Batata $+0,5 \%(\mathrm{~m} / \mathrm{v})$ sacarose & $0,99 \mu \mathrm{g} / \mathrm{L}$ & & \\
\hline Extrato de batata $+0,5 \%(\mathrm{~m} / \mathrm{v})$ de pó de grão de bico & $1,18 \mu \mathrm{g} / \mathrm{L}$ & & \\
\hline Extrato de batata & $1,35 \mu \mathrm{g} / \mathrm{L}$ & \multirow{3}{*}{ An. Stephensi } & \\
\hline Extrato de Batata $+0,5 \%(\mathrm{~m} / \mathrm{v})$ sacarose & $1,97 \mu \mathrm{g} / \mathrm{L}$ & & \\
\hline Extrato de batata $+0,5 \%(\mathrm{~m} / \mathrm{v})$ de pó de grão de bico & $1,77 \mu \mathrm{g} / \mathrm{L}$ & & \\
\hline Extrato de batata & $1,39 \mu \mathrm{g} / \mathrm{L}$ & \multirow{7}{*}{ Ae. Aegypti } & \\
\hline Extrato de Batata $+0,5 \%(\mathrm{~m} / \mathrm{v})$ sacarose & $1,52 \mu \mathrm{g} / \mathrm{L}$ & & \\
\hline Extrato de batata $+0,5 \%(\mathrm{~m} / \mathrm{v})$ de pó de grão de bico & $1,63 \mu \mathrm{g} / \mathrm{L}$ & & \\
\hline $\mathrm{NaCl}(5,0 \mathrm{~g} / \mathrm{L}), \mathrm{Na}_{2} \mathrm{HPO}_{4}(2,5 \mathrm{~g} / \mathrm{L})$ e milhocina $(20 \mathrm{~g} / \mathrm{L})$ & $5,2 \mu \mathrm{g} / \mathrm{L}$ & & $\begin{array}{c}\text { Ernandes, } \\
\text { Del Bianchi } \\
\text { e Oliveira } \\
(2013)\end{array}$ \\
\hline $\begin{array}{l}\mathrm{NaCl}(2,5 \mathrm{mg} / \mathrm{L}), \mathrm{Na} 2 \mathrm{HPO} 4(1,0 \mathrm{mg} / \mathrm{L}), \mathrm{MgSO} 4(0,02 \\
\mathrm{mg} / \mathrm{L}), \mathrm{MnCl} 2(0,005 \mathrm{mg} / \mathrm{L}), 0,5 \mathrm{~g} / \mathrm{L} \text { de feijão }\end{array}$ & $1,57 \mu \mathrm{g} / \mathrm{L}$ & & \multirow{2}{*}{$\begin{array}{c}\text { Devidas, } \\
\text { Pandit e } \\
\text { Vitthalrao } \\
(2014)\end{array}$} \\
\hline $\begin{array}{l}\mathrm{NaCl}(2,5 \mathrm{mg} / \mathrm{L}), \mathrm{Na} 2 \mathrm{HPO} 4(1,0 \mathrm{mg} / \mathrm{L}), \mathrm{MgSO} 4(0,02 \\
\mathrm{mg} / \mathrm{L}), \mathrm{MnCl} 2(0,005 \mathrm{mg} / \mathrm{L}), 0,5 \mathrm{~g} / \mathrm{L} \text { de soja }\end{array}$ & $3,17 \mu \mathrm{g} / \mathrm{L}$ & & \\
\hline $\begin{array}{l}\mathrm{MgCl}_{2}(20,3 \mathrm{~g} / \mathrm{L}), \mathrm{CaCl}_{2}(10,2 \mathrm{~g} / \mathrm{L}), \mathrm{MnCl}_{2}(1,0 \mathrm{~g} / \mathrm{L}) \mathrm{e} \\
\text { água de coco }(100 \mathrm{~mL})\end{array}$ & $15,03 \mathrm{ng} / \mathrm{mL}$ & & $\begin{array}{c}\frac{\text { Prabakaran }}{\text { et al. }} \\
\text { (2008) }\end{array}$ \\
\hline Mingau bruto e farinha de peixe em pó & - & - & $\begin{array}{l}\text { Ghribi, } \\
\text { Zouari e } \\
\text { Jaoua } \\
(2005)\end{array}$ \\
\hline $\begin{array}{l}\mathrm{MgCl}_{2}(20,3 \mathrm{~g} / \mathrm{L}), \mathrm{CaCl}_{2}(10,2 \mathrm{~g} / \mathrm{L}), \mathrm{MnCl}_{2}(1,0 \mathrm{~g} / \mathrm{L}) \mathrm{e} \\
2,5 \% \text { farinha de soja }\end{array}$ & $8,89 \mathrm{ng} / \mathrm{mL}$ & \multirow{3}{*}{ C. quinquefasciatus } & \multirow{3}{*}{$\begin{array}{c}\text { Prabakaran } \\
\text { e } \\
\text { Balamaran } \\
(2006)\end{array}$} \\
\hline $\begin{array}{l}\mathrm{MgCl}_{2}(20,3 \mathrm{~g} / \mathrm{L}), \mathrm{CaCl}_{2}(10,2 \mathrm{~g} / \mathrm{L}), \mathrm{MnCl}_{2}(1,0 \mathrm{~g} / \mathrm{L}) \text { e } 2,5 \\
\% \text { pó de bolo de amendoim }\end{array}$ & $18,84 \mathrm{ng} / \mathrm{mL}$ & & \\
\hline $\begin{array}{l}\mathrm{MgCl}_{2}(20,3 \mathrm{~g} / \mathrm{L}), \mathrm{CaCl}_{2}(10,2 \mathrm{~g} / \mathrm{L}), \mathrm{MnCl}_{2}(1,0 \mathrm{~g} / \mathrm{L}) \mathrm{e} \\
5,0 \% \text { Extrato de farelo de trigo }\end{array}$ & $9,31 \mathrm{ng} / \mathrm{mL}$ & & \\
\hline
\end{tabular}

- não determinado; Bti: B. thuringiensis subsp. israelensis; CL50: Concentração Letal Média 


\section{Considerações Finais}

Baseado nos relatos acima, conclui-se que o solo é o melhor substrato para isolar linhagens de B. thuringiensis e que o meio Ágar Nutriente é o mais utilizado para o cultivo de bactérias entomopatogênicas em laboratório. No entanto, os meios alternativos são altamente econômicos e eficientes para produção de biolarvicidas a base de Bti, reduzindo os custos de produção dessa bactéria em laboratório, e que o Bti é um importante entomopatógeno que pode ser empregado em programas de controle de mosquitos, sendo o Ae. aegypti o vetor mais estudado, devido ser o principal transmissor de arboviroses no Brasil como: zika, chikungunya, dengue e febre amarela urbana. Diante do exposto, o estudo poderá subsidiar pesquisas futuras relacionadas a produção de meios de cultura alternativos a serem utilizados para o controle de mosquitos vetores. É necessário um estudo mais aprofundado das composições químicas do solo e a partir desses estudos desenvolver pesquisas para a fabricação de diferentes meios alternativos com a presença de nutrientes essenciais para o crescimento da bactéria.

\section{Agradecimentos}

À FAPEAM-Fundação de Amparo à Pesquisa do Estado do Amazonas pela concessão das bolsas. Ao Laboratório de Entomologia Médica (LABEM) do Centro de Estudos Superiores de Caxias, Universidade Estadual do MaranhãoCESC/UEMA.

\section{Referências}

Agaisse, H., \& Lereclus, D. (1995). How does Bacillus thuringiensis produce so much insecticidal crystal protein?. Journal of bacteriology, $177(21), 6027$. https://doi.org/10.1128/jb.177.21.6027-6032.1995

Alves, S. B. (1998). Controle microbiano de insetos. 2. ed. Piracicaba, FEALQ.

Angelo, E. A., Vilas-Bôas, G. T., \& Castro-Gómez, R. J. H. (2010). Bacillus thuringiensis: características gerais e fermentação. Semina: Ciências Agrárias, 31(4), 945-958.

Argôlo-Filho, R. C., \& Loguercio, L. L. (2014). Bacillus thuringiensis is an environmental pathogen and host-specificity has developed as an adaptation to human-generated ecological niches. Insects, 5(1), 62-91. https://doi.org/10.3390/insects5010062

Aronson, A. I. (1993). The two faces of Bacillus thuringiensis: insecticidal proteins and post-exponential survival. Molecular microbiology, 7(4), 489-496. https://doi.org/10.1111/j.1365-2958.1993.tb01139.x

Badran, A. H., Guzov, V. M., Huai, Q., Kemp, M. M., Vishwanath, P., Kain, W., ... \& Liu, D. R. (2016). Continuous evolution of Bacillus thuringiensis toxins overcomes insect resistance. Nature, 533(7601), 58-63. https://doi.org/10.1038/nature17938

Barreto, M. R. (2005). Prospecção e Caracterização de Genes de Bacillus thuringiensis com Potencial Para o Controle de Insetos-praga da Cultura da Soja.

Ben-Dov, E. (2014). Bacillus thuringiensis subsp. israelensis and its dipteran-specific toxins. Toxins, 6(4), 1222-1243. https://doi.org/10.3390/toxins6041222

Bergman, N. H., Anderson, E. C., Swenson, E. E., Janes, B. K., Fisher, N., Niemeyer, M. M., ... \& Hanna, P. C. (2007). Transcriptional profiling of Bacillus anthracis during infection of host macrophages. Infection and immunity, 75(7), 3434-3444. https://doi.org/10.1128/IAI.01345-06

Berry, C., O'Neil, S., Ben-Dov, E., Jones, A. F., Murphy, L., Quail, M. A., ... \& Parkhill, J. (2002). Complete sequence and organization of pBtoxis, the toxincoding plasmid of Bacillus thuringiensis subsp. israelensis. Applied and environmental microbiology, 68(10), 5082-5095. https://doi.org/10.1128/AEM.68.10.5082-5095.2002

Boniolo, F. S., Rodrigues, R. C., Prata, A. M. R., López, M. L., Jacinto, T., da Silveira, M. M., \& Berbert-Molina, M. A. (2012). Oxygen supply in Bacillus thuringiensis fermentations: bringing new insights on their impact on sporulation and $\delta$-endotoxin production. Applied microbiology and biotechnology, $94(3)$, 625-636. https://doi.org/10.1007/s00253-011-3746-9

Bravo, A. (1997). Phylogenetic relationships of Bacillus thuringiensis delta-endotoxin family proteins and their functional domains. Journal of bacteriology, 179(9), 2793. https://doi.org/10.1128/jb.179.9.2793-2801.1997

Bravo, A., Gill, S. S., \& Soberon, M. (2007). Mode of action of Bacillus thuringiensis Cry and Cyt toxins and their potential for insect control. Toxicon, 49(4), 423-435. https://doi.org/10.1016/j.toxicon.2006.11.022 
Bravo, A., Gill, S.S., Soberón, M. (2005). Bacillus thuringiensis mechanisms and use. In: Gilbert, L., Iatrou, K., Gill, S (Eds.). Comprehensive Molecular Insect Science (pp. 175-206). Elsevier BV, Amsterdam.

Bravo, A., Likitvivatanavong, S., Gill, S.S \& Soberón, M. (2003). Bacillus thuringiensis: A story of a successful bioinsecticide. Insect Biochemistry and Molecular Biology, 41 (7), 423-431. https://doi.org/10.1016/j.ibmb.2011.02.006

Campanini, E. B., Davolos, C. C., Alves, E. C. C., \& Lemos, M. V. F. (2012). Isolation of Bacillus thuringiensis strains that contain Dipteran-specific cry genes from Ilha Bela (São Paulo, Brazil) soil samples. Brazilian Journal of Biology, 72(2), 243-247. https://doi.org/10.1590/S1519-69842012000200003

Cantón, P. E., Reyes, E. Z., De Escudero, I. R., Bravo, A., \& Soberón, M. (2011). Binding of Bacillus thuringiensis subsp. israelensis Cry4Ba to Cyt1Aa has an important role in synergism. Peptides, 32(3), 595-600. https://doi.org/10.1016/j.peptides.2010.06.005

Capalbo, D.M.F., Vilas-Bôas, G.T., Suzuki, M.T. (2005). Bacillus thuringiensis. Biotecnologia, Ciência e Desenvolvimento, 34 (24), $78-85$.

Carozzi, N. B., Kramer, V. C., Warren, G. W., Evola, S., \& Koziel, M. G. (1991). Prediction of insecticidal activity of Bacillus thuringiensis strains by polymerase chain reaction product profiles. Applied and Environmental Microbiology, 57(11), 3057-3061. https://doi.org/10.1128/aem.57.11.3057-3061.1991

Copping, L. G., \& Menn, J. J. (2000). Biopesticides: a review of their action, applications and efficacy. Pest Management Science: Formerly Pesticide Science, 56(8), 651-676. https://doi.org/10.1002/1526-4998(200008)56:8<651::AID-PS201>3.0.CO;2-U

Couch, T. L. (2000). Industrial fermentation and formulation of entomopathogenic bacteria. In Entomopathogenic Bacteria: from laboratory to field application (pp. 297-316). Springer, Dordrecht.

Crickmore, N., Zeigler, D.R., Schnepf, E., Van Rie, J., Lereclus, D., Baum, J., Bravo, A., \& Dean, D.H. (2020). Bacillus thuringiensis toxin nomenclature. Available on http://www.btnomenclature.info.

Costa, J. R., Rossi, J. R., Marucci, S. C., Alves, E. C. D. C., Volpe, H. X., Ferraudo, A. S., ... \& Desidério, J. A. (2010). Atividade tóxica de isolados de Bacillus thuringiensis a larvas de Aedes aegypti (L.) (Diptera: Culicidae). Neotropical Entomology, 39(5), 757-766. https://doi.org/10.1590/S1519$566 \times 2010000500015$

Damgaard, P. H. (2000). Natural occurrence and dispersal of Bacillus thuringiensis in the environment. In Entomopathogenic bacteria: from laboratory to field application (pp. 23-40). Springer, Dordrecht.

Delécluse, A., Juárez-Pérez, V., \& Berry, C. (2000). Vector-active toxins: structure and diversity. In Entomopathogenic bacteria: from laboratory to field application (pp. 101-125). Springer, Dordrecht. https://doi.org/10.1007/978-94-017-1429-7_6

Deng, C., Peng, Q., Song, F., \& Lereclus, D. (2014). Regulation of cry gene expression in Bacillus thuringiensis. Toxins, 6(7), 2194-2209. https://doi.org/10.3390/toxins6072194

Devidas, P. C., Pandit, B. H., \& Vitthalrao, P. S. (2014). Evaluation of different culture media for improvement in bioinsecticides production by indigenous Bacillus thuringiensis and their application against larvae of Aedes aegypti. The Scientific World Journal, 2014. https://doi.org/10.1155/2014/273030

Ehling-Schulz, M., Lereclus, D., \& Koehler, T. M. (2019). The Bacillus cereus group: Bacillus species with pathogenic potential. Gram-Positive Pathogens, 875-902. https://doi.org/10.1128/microbiolspec.GPP3-0032-2018

El-Kersh, T. A., Ahmed, A. M., Al-Sheikh, Y. A., Tripet, F., Ibrahim, M. S., \& Metwalli, A. A. (2016). Isolation and characterization of native Bacillus thuringiensis strains from Saudi Arabia with enhanced larvicidal toxicity against the mosquito vector Anopheles gambiae (sl). Parasites \& vectors, 9(1), 1-14. https://doi.org/10.1186/ s13071-016-1922-6. https://doi.org/10.1186/s13071-016-1922-6

Ernandes, S., Del Bianchi, V.L., Oliveira, I.M. (2013). Evaluation of two different culture media for the development of biopesticides based on Bacillus thuringiensis and their application in larvae of Aedes aegypti. Acta Scientiarum Technology, 35(1),11-18. https://doi.org/10.4025/actascitechnol.v35i1.13831

Espinasse, S., Chaufaux, J., Buisson, C., Perchat, S., Gohar, M., Bourguet, D., \& Sanchis, V. (2003). Occurrence and linkage between secreted insecticidal toxins in natural isolates of Bacillus thuringiensis. Current microbiology, 47(6), 501-507. https://doi.org/10.1007/s00284-003-4097-2

Fernández-Chapa, D., Ramírez-Villalobos, J., \& Galán-Wong, L. (2019). Toxic Potential of Bacillus thuringiensis: An Overview. Protecting Rice Grains in the Post-Genomic Era. https://doi.org/10.5772/intechopen.85756

Galzer, E. C. W., \& Azevedo Filho, W. S. (2016). Utilização do Bacillus thuringiensis no controle biológico de pragas. Revista Interdisciplinar de Ciência Aplicada, 1(1), 13-16.

Ghribi, D., Zouari, N., \& Jaoua, S. (2005). Improvement of bioinsecticides production through adaptation of Bacillus thuringiensis cells to heat treatment and $\mathrm{NaCl}$ addition. Journal of applied microbiology, 98(4), 823-831. https://doi.org/10.1111/j.1365-2672.2004.02490.x

Glare, T. R., \& O'Callaghan, M. H. (2000). Bacillus thuringiensis: Biology, Ecology and Safety. John Wiley\&Sons. Inc., New York, NY. 
Gobatto, V., Giani, S. G., Camassola, M., Dillon, A. J. P., Specht, A., \& Barros, N. M. (2010). Bacillus thuringiensis isolates entomopathogenic for Culex quinquefasciatus (Diptera: Culicidae) and Anticarsia gemmatalis (Lepidoptera: Noctuidae). Brazilian Journal of Biology, 70(4), 1039-1046.6. https://doi.org/10.1590/S1519-69842010000500018

González Jr, J., \& Carlton, B. C. (1984). A large transmissible plasmid is required for crystal toxin production in Bacillus thuringiensis variety israelensis. Plasmid, 11(1), 28-38. https://doi.org/10.1016/0147-619x(84)90004-0

Guz, K., Bugla-Ploskonska, G., \& Doroszkiewicz, W. (2009). The Occurrence, Biodiversity and Toxicity of Bacillus thuringiensis Strains Isolated from the Insect Pest Lymantria dispar(Poland). Polish journal of microbiology, 58(2), 155-161.

Habib, M.E.M., Andrade, C.F.S. (1996). Bactérias entomopatogênicas. In: Alves, S.B (Ed). Controle Microbiano de Insetos (pp. 383-446). FEALQ, Piracicaba

Höfte, H., \& Whiteley, H. R. (1989). Insecticidal crystal proteins of Bacillus thuringiensis. Microbiology and Molecular Biology Reviews, 53(2), 242-255.

Johnson, D. E., \& McGaughey, W. H. (1996). Contribution of Bacillus thuringiensis spores to toxicity of purified Cry proteins towards Indianmeal moth larvae. Current microbiology, 33(1), 54-59. https://doi.org/10.1007/s002849900074.

Konecka, E., Baranek, J., Hrycak, A., \& Kaznowski, A. (2012). Insecticidal activity of Bacillus thuringiensis strains isolated from soil and water. The Scientific World Journal, 2012. https://doi.org/10.1100 / 2012/710501

Kuo, W. S., \& Chak, K. F. (1996). Identification of novel cry-type genes from Bacillus thuringiensis strains on the basis of restriction fragment length polymorphism of the PCR-amplified DNA. Applied and Environmental Microbiology, 62(4), 1369-1377.

Lereclus, D., Arantes, O., Chaufaux, J., \& Lecadet, M. M. (1989). Transformation and expression of a cloned $\delta$-endotoxin gene in Bacillus thuringiensis. FEMS microbiology letters, 60(2), 211-217. https://doi.org/10.1111/j.1574-6968.1989.tb03448.x

Li, J., Carroll, J., \& Ellar, D. J. (1991). Crystal structure of insecticidal $\delta$-endotoxin from Bacillus thuringiensis at $2.5 \AA$ resolution. Nature, 353(6347), 815821. https://doi.org/10.1038/353815a0

Liu, B. L., \& Tzeng, Y. M. (1998). Optimization of growth medium for the production of spores from Bacillus thuringiensis using response surface methodology. Bioprocess Engineering, 18(6), 413-418. https://doi.org/10.1007/PL00008999

Liu, Q., Hallerman, E., Peng, Y., \& Li, Y. (2016). Development of Bt rice and Bt maize in China and their efficacy in target pest control. International journal of molecular sciences, 17(10), 1561. https://doi.org/10.3390/ijms17101561

Lobo, K. D. S., Soares-da-Silva, J., Silva, M. C. D., Tadei, W. P., Polanczyk, R. A., \& Pinheiro, V. C. S. (2018). Isolation and molecular characterization of Bacillus thuringiensis found in soils of the Cerrado region of Brazil, and their toxicity to Aedes aegypti larvae. Revista Brasileira de Entomologia, 62(1), 5-12. https://doi.org/10.1016/j.rbe.2017.11.004

Marrone, P.G. (2019). Pesticidal natural products-status and future potential. Pest Management Science, 75 (9), 2325-2340. https://doi.org/10.1002/ps.5433

Maagd, R. A., Bravo, A., Berry, C., Crickmore, N., \& Schnepf, H. E. (2003). Structure, diversity, and evolution of protein toxins from spore-forming entomopathogenic bacteria. Annual review of genetics, 37(1), 409-433. https://doi.org/10.1146/annurev.genet.37.110801.143042

Meadows, M. P. (1993). Bacillus thuringiensis in the environment: ecology and risk assessment. Bacillus thuringiensis, An environmental biopesticide: Theory and Practice, 193-220.

Medeiros, P. T., Sone, E. H., Soares, C. M. S., Dias, J. M. C. D. S., \& Monnerat, R. G. (2006). Evaluation of insecticides based on Bacillus thuringiensis in the control of the diamondback moth. Horticultura Brasileira, 24(2), 245-248. https://doi.org/10.1590/S0102-05362006000200026

Monnerat, R. G., Dias, D. G. S., Silva, S. F. D., Martins, E. S., Berry, C., Falcão, R., ... \& Soares, C. M. S. (2005). Screening of Bacillus thuringiensis strains effective against mosquitoes. Pesquisa Agropecuária Brasileira, 40(2), 103-106. https://doi.org/10.1590/S0100-204X2005000200001

Onofre, J., Pacheco, S., Torres-Quintero, M. C., Gill, S. S., Soberon, M., \& Bravo, A. (2020). The Cyt1 Aa toxin from Bacillus thuringiensis inserts into target membranes via different mechanisms in insects, red blood cells, and lipid liposomes. Journal of Biological Chemistry, 295(28), 9606-9617. https://doi.org/10.1074/jbc.RA120.013869

Ootani, M. A., Ramos, A. C. C., de Azevedo, E. B., de Oliveira Garcia, B., dos Santos, S. F., \& de Sousa Aguiar, R. W. (2011). Avaliação da toxicidade de estirpes de Bacillus thuringiensis para Aedes aegypti Linneus (Díptera: Culicidae). Journal of Biotechnology and Biodiversity, 2(2), 37-43. https://doi.org/10.20873/jbb.uft.cemaf.v2n2.ootani

Pérez, C., Fernandez, L. E., Sun, J., Folch, J. L., Gill, S. S., Soberón, M., \& Bravo, A. (2005). Bacillus thuringiensis subsp. israelensis Cyt1Aa synergizes Cry11Aa toxin by functioning as a membrane-bound receptor. Proceedings of the National Academy of Sciences, 102(51), 18303-18308. https://doi.org/10.1073/pnas.0505494102 
Pigott, C. R., \& Ellar, D. J. (2007). Role of receptors in Bacillus thuringiensis crystal toxin activity. Microbiology and molecular biology reviews, 71(2), 255281. https://doi.org/10.1128/MMBR.00034-06

Polanczyk, R. A. (2004). Estudos de Bacillus thuringiensis Berliner visando ao controle de Spodoptera frugiperda (JE Smith) (Doctoral dissertation, Universidade de São Paulo).

Polanczyk, R. A., Zanúncio, J. C., \& Alves, S. B. (2009). Relationship between chemical properties of the soil and the occurrence of Bacillus thuringiensis. Ciência Rural, 39(1), 1-5. https://doi.org/10.1590/\$0103-84782009000100001

Polanczyk, R.A. \& Alves, S. (2003). Bacillus thuringiensis: Uma breve revisão. Agrociencia Uruguay, 7(2), 1-10.

Silva, S. F., Dias, J. D. S., \& Monnerat, R. (2002). Comparação entre três métodos de isolamento de bacilos entomopatogênicos. Embrapa Recursos Genéticos e Biotecnologia-Circular Técnica (INFOTECA-E).

Poopathi, S., \& Abidha, S. (2011). Coffee husk waste for fermentation production of mosquitocidal bacteria. Journal of economic entomology, 104(6), 18161823. https://doi.org/10.1603/EC11125

Poopathi, S., \& Abidha, S. (2012). The use of clarified butter sediment waste from dairy industries for the production of mosquitocidal bacteria. International journal of dairy technology, 65(1), 152-157. https://doi.org/10.1111/j.1471-0307.2011.00745.x

Poopathi, S., \& Kumar, K. A. (2003). Novel fermentation media for production of Bacillus thuringiensis subsp. israelensis. Journal of economic entomology, 96(4), 1039-1044. https://doi.org/10.1093/jee/96.4.1039

Prabakaran, G., \& Balaraman, K. (2006). Development of a cost-effective medium for the large scale production of Bacillus thuringiensis var israelensis. Biological Control, 36(3), 288-292. https://doi.org/10.1016/j.biocontrol.2005.09.018

Prabakaran, G., Hoti, S. L., Manonmani, A. M., \& Balaraman, K. (2008). Coconut water as a cheap source for the production of $\delta$ endotoxin of Bacillus thuringiensis var. israelensis, a mosquito control agent. Acta tropica, 105(1), 35-38. https://doi.org/10.1016/j.actatropica.2007.09.002

Praça, L. B., Batista, A. C., Martins, É. S., Siqueira, C. B., Dias, D. G. D. S., Gomes, A. C. M. M., ... \& Monnerat, R. G. (2004). Estirpes de Bacillus thuringiensis efetivas contra insetos das ordens Lepidoptera, Coleoptera e Diptera. Pesquisa Agropecuária Brasileira, 39(1), 11-16. https://doi.org/10.1590/S0100-204X2004000100002

Raymond, B. (2017). The biology, ecology and taxonomy of Bacillus thuringiensis and related bacteria. In Bacillus thuringiensis and Lysinibacillus sphaericus (pp. 19-39). Springer, Cham.

Reyaz, A. L., Gunapriya, L., \& Arulselvi, P. I. (2017). Molecular characterization of indigenous Bacillus thuringiensis strains isolated from Kashmir valley. 3 Biotech, 7(2), 1-11. https://doi.org/10.1007/s13205-017-0756-z.

Rossa, C. A., Yantorno, O. M., Arcas, J. A., \& Ertola, R. J. (1990). Organic and inorganic nitrogen source ratio effects on Bacillus thuringiensis var. israelensis delta-endotoxin production. World Journal of Microbiology and Biotechnology, 6(1), 27-31. https://doi.org/10.1007/BF01225351

Salama, H. S., Foda, M. S., Dulmage, H. T., \& El-Sharaby, A. (1983). Novel fermentation media for production of $\delta$-endotoxins from Bacillus thuringiensis. Journal of Invertebrate Pathology, 41(1), 8-19. https://doi.org/10.1016/0022-2011(83)90231-8

Sanchis, V. (2011). From microbial sprays to insect-resistant transgenic plants: history of the biospesticide Bacillus thuringiensis. A review. Agronomy for sustainable development, 31(1), 217-231. https://doi.org/10.1051/agro/2010027

Saraiva, J.F., Maitra, A., Galardo, A.K.R \& Scarpassa, V.M. (2019). First record of Aedes (Stegomyia) albopictus in the state of Amapá, northern Brazil. Acta Amazonica, 49 (1), 71-74. https://doi.org/10.1590/1809-4392201802771

Saraswathy, N., \& Kumar, P. A. (2004). Protein engineering of delta-endotoxins of Bacillus thuringiensis. Electronic Journal of Biotechnology, 7(2), 178-188.

Sarrafzadeh, M. H. (2012). Nutritional requirements of Bacillus thuringiensis during different phases of growth, sporulation and germination evaluated by plackett-burman method. https://doi.org/10.30492/IJCCE.2012.5936

Schnepf, H. E., \& Whiteley, H. R. (1981). Cloning and expression of the Bacillus thuringiensis crystal protein gene in Escherichia coli. Proceedings of the National Academy of Sciences, 78(5), 2893-2897. https://doi.org/10.1073/pnas.78.5.2893

Silva, N. D. (2008). Caracterização e seleção de isolados de Bacillus thuringiensis efetivos contra Sitophilus oryzae L., 1763.

Soares-da-Silva, J., Pinheiro, V. C. S., Litaiff-Abreu, E., Polanczyk, R. A., \& Tadei, W. P. (2015). Isolation of Bacillus thuringiensis from the state of Amazonas, in Brazil, and screening against Aedes aegypti (Diptera, Culicidae). Revista Brasileira de Entomologia, 59(1), 1-6. https://doi.org/10.1016/j.rbe.2015.02.001 
Soares-da-Silva, J., Queirós, S.G., Aguiar, J.S., Viana, J.L., Neta, M.D.R.A.V., Silva, M.C., Pinheiro, V.C.S., Polanczyk, R.A., Carvalho-Zilse., G.A \& Tadei, W.P. (2017). Molecular characterization of the gene profile of Bacillus thuringiensis Berliner isolated from Brazilian ecosystems and showing pathogenic activity against mosquito larvae of medical importance. Acta Tropica, 176, 197-205. https://doi.org/10.1016/j.actatropica.2017.08.006

Soccol, C. R., Pollom, T. E., Fendrich, R. C., Prochmann, F. A., Mohan, R., Blaskowski, M. M. M., ... \& Soccol, V. T. (2009). Development of a low cost bioprocess for endotoxin production by Bacillus thuringiensis var israelensis intended for biological control of Aedes aegypti. Brazilian Archives of Biology and Technology, 52(SPE), 121-130. https://doi.org/10.1590/S1516-89132009000700017

Tan, F., Zhu, J., Tang, J., Tang, X., Wang, S., Zheng, A., \& Li, P. (2009). Cloning and characterization of two novel crystal protein genes, cry54Aa1 and cry30Fa1, from Bacillus thuringiensis strain BtMC28. Current microbiology, 58(6), 654-659. https://doi.org/10.1007/s00284-009-9386-y

Tissera, H. A., Samaraweera, P. C., Jayamanne, B. D. W., Janaki, M. D. S., U Chulasiri, M. P. P., Rodrigo, C., \& Fernando, S. D. (2018). Use of Bacillus thuringiensis israelensis in integrated vector control of Aedes sp. in Sri Lanka: a prospective controlled effectiveness study. Tropical Medicine \& International Health, 23(2), 229-235. https://doi.org/10.1111/tmi.13015

Van Frankenhuyzen, K. (2009). Insecticidal activity of Bacillus thuringiensis crystal proteins. Journal of invertebrate pathology, 101(1), 1-16. https://doi.org/10.1016/j.jip.2009.02.009

Van Frankenhuyzen, K. (2013). Cross-order and cross-phylum activity of Bacillus thuringiensis pesticidal proteins. Journal of Invertebrate Pathology, 114(1), 76-85. https://doi.org/10.1016/j.jip.2013.05.010

Viana, J. L., Soares-da-Silva, J., Vieira-Neta, M. R. A., Tadei, W. P., Oliveira, C. D., Abdalla, F. C., ... \& Pinheiro, V. C. S. (2021). Isolates of Bacillus thuringiensis from Maranhão biomes with potential insecticidal action against Aedes aegypti larvae (Diptera, Culicidae). Brazilian Journal of Biology, 81(1), 114-124. https://doi.org/10.1590/1519-6984.223389

Vieira-Neta, M. R. A., Soares-da-Silva, J., Viana, J. L., Silva, M. C., Tadei, W. P., \& Pinheiro, V. C. S. (2020). Strain of Bacillus thuringiensis from Restinga, toxic to Aedes (Stegomyia) aegypti (Linnaeus) (Diptera, Culicidae). Brazilian Journal of Biology, (AHEAD). https://doi.org/10.1590/1519-6984.228790

Wang, J., Boets, A., Van Rie, J., \& Ren, G. (2003). Characterization of cry1, cry2, and cry9 genes in Bacillus thuringiensis isolates from China. Journal of Invertebrate Pathology, 82(1), 63-71. https://doi.org/10.1016/s0022-2011(02)00202-1

World Health Organization. (1985). Informal consultation on the development of Bacillus sphaericus as microbial larvicide. Geneva: UNDP: World Bank: WHO, 24p. Special Programme for Research and Training in Tropical Diseases (TDR).

Yamamoto, T., \& Dean, D. H. (2000). Insecticidal proteins produced by bacteria pathogenic to agricultural pests. In Entomopathogenic bacteria: from laboratory to field application (pp. 81-100). Springer, Dordrecht.

Zhong, W., Shou, Y., Yoshida, T. M., \& Marrone, B. L. (2007). Differentiation of Bacillus anthracis, B. cereus, and B. thuringiensis by using pulsed-field gel electrophoresis. Applied and environmental microbiology, 73(10), 3446-3449. https://doi.org/10.1128/AEM.02478-06

Zogo, B., Tchiekoi, B. N. C., Koffi, A. A., Dahounto, A., Alou, L. P. A., Dabiré, R. K., ... \& Pennetier, C. (2019). Impact of sunlight exposure on the residual efficacy of biolarvicides Bacillus thuringiensis israelensis and Bacillus sphaericus against the main malaria vector, Anopheles gambiae. Malaria journal, 18(1), 1-9. https://doi.org/ 10.1186/ s12936-019-2687-0 